\title{
Relationship between Academic Self-efficacy Believed of College Students and Academic Performance.
}

\author{
Ali Garba Kolo ${ }^{\mathrm{a}}$, Wan Munira Binti Wan Jaafar*b ${ }^{\mathrm{b}}$, Nobaya Binti Ahmad ${ }^{\mathrm{c}}$ \\ ${ }^{b}$ Faculty of Human Ecology, University Putra Malaysia ${ }^{a}$ Mai Idris Alooma Polytechnic Gaidam, Yobe State, \\ Nigeria
}

\begin{abstract}
This paper investigate the levels of students' academic self-efficacy beliefs and relationship between academic self-efficacy with students' academic performance among final year students' in one of Nigerian Colleges of education. Questionnaire was used as the means of data collection. A total sample of 339 respondents who were stratified and randomly selected from five faculties of the College participated in the research. The respondents were between the age of 19 to 34 years old with mean age equals $23.19(\mathrm{SD}=2.64)$. The findings revealed that, $80.82 \%$ of the respondents have higher levels of academic self-efficacy in the College. Also positive and significant relationship between academic self-efficacy beliefs with students' academic performance $(\mathbf{r}=\mathbf{0 . 3 4 2}, \mathbf{p}<\mathbf{0 . 0 1})$ were recorded. Therefore, it is recommended that students' should be exposing to the kind of self-efficacy intervention program in order for the students' to be having a kind of confidence to feel that, they can really perform well and deal with all academic related task positively, which in turn improve academic achievement of students' positively.
\end{abstract}

Keywords- Academic Self-Efficacy, Academic Performance, Relationship, College Students'.

\section{INTRODUCTION}

Academic performance is undoubtedly becoming a research after the heart of social scientists particularly psychologists in their struggle to know what determine academic performance of students. In recent time, previous studies have indicated that students' academic performance in schools have been affected by many psychosocial factors such as motivation, attitude, interaction, academic self-efficacy, family, stress etc. (Li, 2012; Adediwura and Tayo, 2007). Academic self-efficacy is the belief that an individual can efficiently perform some tasks that usually influence his or her own behavior in a positive way. Self-efficacy was originated from social cognitive theory which states a significant interaction between individual, environment, behavior and cognitive factors (Bandura, 1997). Self-efficacy is a psychological concept that influence healthy behaviors (Von Ah, Ebert, Ngamviro, Park, Kang, 2004). "Self-efficacy is a belief in one's capabilities to organize and execute the causes of action required to manage prospective situation' (Bandura, 1986). Selfefficacy implies the belief that we are efficient to do something determine our behavior at the end. Meaning selfefficacy played a great role in determine how an individual feelings and thought motivated themselves, which then ultimately influenced their behavior and the outcome (Bandura, 1986). According to Schunk (1991) academic self-efficacy refers to individuals' convictions that they can successfully deliver any academic tasks at designated levels. Moreover, "Academic self-efficacy refers to students' perceptions of their competence to do their classwork" (Midgley et al., 2000). Bandura theory of self-efficacy argued that, human behavior can be predicted by an individual levels of confidence in their ability to succeed in a specific task (Bandura, 1997). Self-efficacy is one of the important aspect of social cognitive theory because most of the individual level of self-efficacy are from external experiences and self-perception which it determine the results of tasks and circumstances they encountered (Bandura, 1997; Miller \& Dollard, 1941; Bandura 1986).Researches have revealed that self-efficacy play a significant influence on human behavior and this cannot be overemphasized because people use to have high self-efficacy in some situation and lower in others, this shows that it is a behavioral change and it depends on one's situation or condition (Bandura, 1997; Ando \&Asakura, 2007). The application of self-efficacy theory in this present study is that, students who possessed a high level of academic self-efficacy believed were more likely to attempt most of the academic challenges tasks, resist longer at them and exert more efforts in the academic process. If highly efficacious student fail to perform well, they associate the outcome to a lack of effort or an adverse environment. But when they succeed, they attribute their 
performance to their abilities. They belief that it was their abilities and confidence caused the performance that affect the outcome rather than their actual abilities (Bandura, 1986). Moreover, Bandura (1986) list four factors that determine self-efficacy: enactive mastery experience, vicarious experience, verbal persuasion, and physiological and emotional states. The most influential among these factors is enactive mastery experience, which has to do with individual experience with success or failure in the past situation. Information gathered from the experiences is internalized because past success increase self-efficacy and repeated failure lower it, but it depend on individual levels of capabilities. (Bandura, 1986). In vicarious experience individual compare themselves to peers whom they perceived are similar in capabilities and intelligence to themselves, by watching peers succeed increase observers self-efficacy (Bandura, 1986). Verbal persuasion helps an individual to clear his or her doubt of capabilities, that they possess than ability and confidence needed for success at a given tasks (Bandura, 1986). Emotional state can either be a negative or positive which affect interpretation of an event's outcome, if the result is positive it raises one's self-efficacy, while if it is negative lower it (Bandura, 1986).

Self-efficacy predicts intellectual performance better than skills alone, and directly influences academic performance through cognition (Tenaw, 2013). Although past performance raises self-efficacy, it is student interpretation of past success and failures that may be responsible for subsequent success (Tenaw, 2013). Perceived self-efficacy predicts future performance better than past achievement (Bandura, 1986; Chemers et al., 2001). Self-efficacy beliefs also contribute to student academic performance because they influence thought, process, motivation, and behavior (Bandura, 1997). Student academic performance may be fluctuated because of the varying belief in self-efficacy which depend on the performance outcome of the past experience (Tenaw, 2013). "Therefore who regarded themselves as inefficacious shy away from difficult task, slacken their effort and give up readily in the face of difficulties, dwell on their personal deficiencies, lower their aspirations, and suffer much anxiety and stress. Such self-efficacy misgivings undermine performance" (Bandura, 1986. P395).

Previous studies on academic self-efficacy believed on student academic performance has been a topic of interest to many researchers and particularly social scientists. Because it was revealed by many findings that academic self-efficacy was strongly associated with student academic performance. For example; in a studied conducted by Tenaw (2013) on a relationship between self-efficacy, academic achievement and gender in analytical chemistry at DebreMarkos College of Teacher education, Ethiopia. The results from Pearson Correlation analysis showed that, there was significant and positive relationship between self-efficacy and academic achievement ( $\mathrm{r}=0.385, \mathrm{p}<0.01)$. Li (2012) studied attitude, self-efficacy, effort and academic achievement among students of City University of Hong Kong. The researcher reported that academic selfefficacy $(\beta=0.355, \mathrm{p}<.01)$ could significantly predict academic achievement better than attitude and effort in the study. Furthermore, Adeyemo (2007). Examined the moderating influence of emotional intelligence on the link between academic self-efficacy and achievement among undergraduate students of University of Ibadan, Nigeria. After analyzing the results, the study revealed a significant and positive correlation between academic self-efficacy with academic achievement $(r=0.28, \mathrm{p}<0.01)$. Similarly, Zajacova et al., (2005). Investigated the joint effects of academic self-efficacy and stress on the academic performance of students in one of the City University of New York. The findings demonstrated that self-efficacy has a significant and positive influence on student academic performance. In contrast to the above viewed that self-efficacy is associated with student academic performance. Fenollar et al., (2007). Conducted a study on students' academic performance as an integrative conceptual framework and empirical analysis in University of Murcia, Spain. 553 students were selected as sampled from different faculties in which Male $40 \%$ and Female $60 \%$ were examined. The results from Structural Equation Modelling revealed that there was no direct of relationship between self-efficacy and academic performance of the students. Similarly, Strelnieks (2003). Examined the relationship of student's domain specific self-concepts and self-efficacy to academic performance of minority students. The researcher found that whether self-efficacy could influence student academic performance it depended on some external factors like gender and socio-economic status of the students. The results revealed that self-efficacy could only predict females' academic performance and failed to predict male's academic achievement. And also selfefficacy can only predict academic performance of students with higher socio-economic background and failed to predict students with poor socio-economic status. Based on the reviewed of different literature on academic self-efficacy concept it appeared without doubt that the concept is universal and very important component in understanding students' academic performance because it is has different predictive power on different individuals (Strelnieks, 2003). In line with this, more studies need to be done in order to have a unanimous result on the academic self-efficacy on student academic performance, this led the researchers to raise the following issues;

1.1 Research Questions 
1. What are the levels of students' academic self-efficacy belief of Potiskum College of education students'?

2. Is there any relationship between academic self-efficacy believed with academic performance in Potiskum College of education?

1.2Research Objective

1. To identify the levels of students academic self-efficacy in the College

2. To determine the relationship between academic self-efficacy believed with students' academic performance in Potiskum College of education

1.3Research Hypothesis

There is a significant and positive relationship between academic self-efficacy believed and students' academic performance in Potiskum College of education.

\section{METHODOLOGY}

2.1 Research Design

In present study, quantitative research approach with correlational research design was adopted in order to investigate the relationship between academic self-efficacy and students' academic performance. Questionnaire was used as a means of data collection. A total sample of 339 students was stratified and randomly selected from five faculties/schools in Federal College of Education (Technical) Potiskum, Yobe State, Nigeria to serve as the respondents.

2.2 Instrumentation

\subsubsection{Academic performance}

In this study, student academic performance was measured based on actual or current CGPA of final year students of Federal College of Education (Technical) Potiskum, Yobe State, Nigeria which is the Sum of first and second semester Grade Point Average (GPA) of the students divided by two which gave their current CGPA.

\subsubsection{Academic Self-Efficacy}

The questionnaire on academic self-efficacy was measured based on 8 items which were adapted from Muris, (2001). All the questions utilized a Likert scale, ranging from 1 (not at all) to 5 (very well) and Cronbach's alpha of the items was 0.82 . In present study, all the items were modified in order to fit the study and example of the items are "My lecturer help me when I get stuck on my academic tasks", "I can study and do other things that are not related to my study". The items were measure on a five-point Likert scale from 1=strongly disagree to $5=$ strongly agree and the Cronbach alpha obtained was 0.864 which was above the general accepted minimum value of 0.70 for reliability (George and Mallery, 2003).

\subsection{Data Analysis}

The collected data were analyze using descriptive and inferential statistics i.e. in descriptive statistics mean, standard deviation, frequency and percentage were used to measure the level of students academic selfefficacy. While in inferential statistics, Pearson's Correlation was used to measure the relationship between academic self-efficacy believe with students' academic performance.

\section{RESULTS AND DISCUSSION}

Table 1. Contained the background of the respondents, which is described as follows. The results displayed that majority $(72.3 \%)$ of the respondents were male and $27.7 \%$ were female. The respondents were between the age of 19 to 34 years old with mean age equals $23.19(\mathrm{SD}=2.64)$. The data shows that more than half of the respondents (75.8\%) were in the age category of 19-24 years old followed by respondents between $25-29$ years old $20.6 \%$ and lastly, $3.6 \%$ of the respondents were in the age category of 30 years and above. However, on the faculties of the respondents, the findings reveals that majority $(25.1 \%)$ of the respondents were from the faculty of Science, $24.5 \%$ of the respondents were from the faculty Technical, $22.1 \%$ of the respondents were from the faculty of Education, $15.3 \%$ of the respondents were from the faculty of Business and finally $13.0 \%$ of the respondents were from the faculty of Vocational.

Table 3.1 Background of the Respondents ( $n=339)$

\begin{tabular}{|l|l|l|l|l|l|l|}
\hline Variable & Freq & $(\%)$ & Mean & SD & Min. & Max. \\
\hline Age (Years Old) & & & 23.19 & $\mathbf{2 . 6 4}$ & $\mathbf{1 9}$ & $\mathbf{3 4}$ \\
\hline
\end{tabular}


Relationship between Academic Self-efficacy Believed of College Students and Academic Performance.

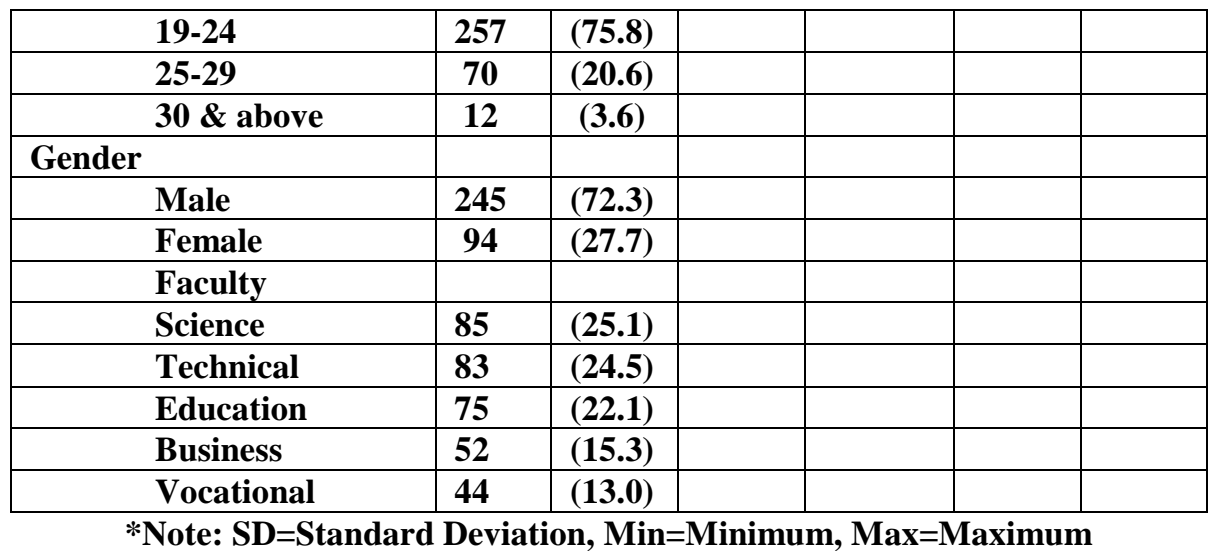

Table 2. Present the levels of students' academic self-efficacy in which the findings revealed that 24 $(7.09 \%)$ of the students have low academic self-efficacy, 41 (12.09\%) of the students have moderate academic self-efficacy and majority 274 (80.82\%) of the respondents have high academic self-efficacy. Meaning, majority of the respondents in present study believed that they can deal with their academic tasks and all related school activities positively in which in return, it improved their academic performance significantly. According to Bandura, (1997); Ando \&Asakura, (2007), people use to have high self-efficacy in some situation and lower in others, this shows that it is a behavioral change and it depends on one's situation or condition. Furthermore, selfefficacy theory argued that, individuals who possessed a high level of academic self-efficacy believed were more likely to attempt most of the academic challenges tasks, resist longer at them and exert more efforts in the academic process. If highly efficacious student fail to perform well, they associate the outcome to a lack of effort or an adverse environment. But when they succeed, they attribute their performance to their abilities. They belief that it was their abilities and confidence caused the performance that affect the outcome rather than their actual abilities (Bandura, 1986).

Table 3.2 Levels of Students Academic Self-Efficacy

\begin{tabular}{|l|l|l|}
\hline Levels & Frequency & Percentage \\
\hline Low Academic Self-Efficacy & 24 & 7.09 \\
\hline Moderate Academic Self-Efficacy & 41 & 12.09 \\
\hline High Academic Self-Efficacy & 274 & $\mathbf{8 0 . 8 2}$ \\
\hline Total & 339 & 100 \\
\hline
\end{tabular}

Pearson correlation (r) was applied to determine the relationship between student academic selfefficacy and student academic performance. The results of Pearson Product-Moment Correlation in Table 3. Showed that, there is a significant and positive relationship between student academic self-efficacy belief and academic performance $(\mathbf{r}=\mathbf{0 . 3 4 2}, \mathbf{p}<\mathbf{0 . 0 1})$. Based on the outcome of this analysis, the null hypotheses was rejected. Therefore, it can be concluded that there is a significant and positive relationship between student academic self-efficacy and academic performance in Potiskum College of education.

Table 3.3Correlational Analysis between Student Academic Self-efficacyBelief and Academic Performance $(\mathbf{n}=339)$

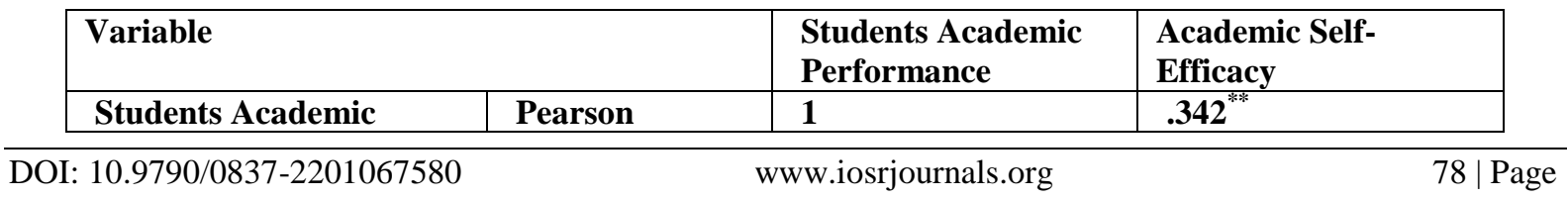


Relationship between Academic Self-efficacy Believed of College Students and Academic Performance.

\begin{tabular}{|l|l|l|l|}
\hline \multirow{3}{*}{ Performance } & Correlation & & \\
\cline { 2 - 4 } & Sig. (2-tailed) & & $\mathbf{. 0 0 0}$ \\
\cline { 2 - 4 } & $\mathbf{N}$ & $\mathbf{3 3 9}$ & $\mathbf{3 3 9}$ \\
\hline Academic Self-Efficacy & $\begin{array}{l}\text { Pearson } \\
\text { Correlation }\end{array}$ & $\mathbf{. 3 4 2}$ & $\mathbf{1}$ \\
\cline { 2 - 4 } & Sig. (2-tailed) & $\mathbf{. 0 0 0}$ & $\mathbf{3 3 9}$ \\
\cline { 2 - 4 } & $\mathbf{N}$ & $\mathbf{3 3 9}$ & \\
\hline \multirow{2}{*}{$*$ Correlation is significant at the 0.01 level (2-tailed). } & \\
\hline
\end{tabular}

The finding is similar with past studied done by Li (2012), Tenaw (2013), Zajacova et al., (2005) and Adeyemo (2007) who found that academic self-efficacy was significantly correlated with student academic performance. And is in line with Bandura (1986) who stated that self-efficacy played a great role in determining how an individual feelings and thought motivated themselves, which then ultimately influenced their behavior and the outcome. Tenaw (2013) argued that Self-efficacy predicts intellectual performance better than skills alone, and directly influences academic performance through cognition. Although past performance raises selfefficacy, it is student interpretation of past success and failures that may be responsible for subsequent success (Tenaw, 2013). Perceived self-efficacy predicts future performance better than past achievement (Bandura, 1986; Chemers et al., 2001). Self-efficacy beliefs also contribute to student academic performance because they influence thought, process, motivation, and behavior (Bandura, 1997). The present study has revealed that academic self-efficacy is higher among the Potiskum College of education students because it has serious positive influence to student academic performance, that was why Bandura (1986). Stated that if highly efficacious student fail to perform well, they associate the outcome to a lack of effort or an adverse environment. But when they succeed, they attribute their performance to their abilities. They belief that it was their abilities and confidence caused the performance that affect the outcome rather than their actual abilities.

\section{CONCLUSION AND RECOMMENDATION}

In present study, it can be concluded that, the level of students' academic self-efficacy was high considering the fact that, $80.82 \%$ of the respondents were in the High category. Also there was a significant and positive relationship between academic self-efficacy with academic performance. So, based on the findings of this research it is recommended that students' should be exposing to the kind of self-efficacy intervention program in order for the students' to be having a kind of confidence to feel that, they can really perform well and deal with all academic related task positively, which in turn improve academic achievement of students' positively. This study was conducted in only one of the Nigerian Colleges of education which generality of the findings is only applicable to the study population. Hence, future research should employ more samples in order to have good and general results on students' academic self-efficacy believed.

\section{REFERENCES}

[1] Adediwura, A. A., \&Tayo, B. (2007). Perception of teachers' knowledge, attitude and teaching skills as predictor of academic performance in Nigerian secondary schools. Educational Research and Reviews, 2(7), 165.

[2] Adeyemo, D. A. (2007). Moderating influence of emotional intelligence on the link between academic self-efficacy and achievement of university students. Psychology \& Developing Societies, 19(2), 199-213.

[3] Ando, M., Asakura, T. (2007) Psychosocial factors associated with smoking and drinking among Japanese early Adolescents boys and girls: Cross-sectional study. Biopsychosocial Medicine, 1 (13), 1 10.

[4] Bandura, A. (1986). Social foundations of thought and action: A social cognitive theory. Englewood Cliffs, NJ: Prentice-Hall.

[5] Bandura, A. (1997). Self-efficacy: The exercise of control. New York: W.H. Freeman and Company.

[6] Chemers, M. M., Hu, L., \& Garcia, B. F. (2001). Academic self-efficacy and first-year College student performance and judgment. Journal of educational psychology, 93(1), 55-64.

[7] Fenollar, P., Román, S., \& Cuestas, P. J. (2007). University students' academic performance: An integrative conceptual framework and empirical analysis. British Journal of Educational Psychology, 77(4), 873-891. 
[9] George, D., \&Mallery, P. (2003). SPSS for Windows step by step: A simple guide and reference.11.0 update (4th Ed.).Boston: Allyn \&Bacon.

[10] Li, L. K. Y. (2012). A study of the attitude, self-efficacy, effort and academic achievement of city U students towards research methods and statistics. Discovery SS Student E-Journal, 1: 154-183.

[11] Midgley, C., Maehr, M. L., Hruda, L. Z., Anderman, E.,Anderman, L., Freeman, K. E., \&Urdan, T. (2000). Manual for the patterns of adaptive learning scales. Ann Arbor, 1001, 48109-1259.

[12] Miller, N., \& Dollard, J. (1941) Social learning and imitation. New Haven: Yale University Press.

[13] Muris, P. (2001). A brief questionnaire for measuring self-efficacy in youths. Journal of Psychopathology and behavioral Assessment. 23, 145149

[14] Schunk, D. H. (1991). Self-efficacy and academic motivation. Educational psychologist, 26(3-4), $207-$ 231.

[15] Strelnieks, M. (2003). The relationship of students' domain specific self-concepts and self-efficacy to academic performance. "Unpublished PhD Thesis". Marquette University, Wisconsin.

[16] Tenaw, Y. A. (2013). Relationship between self-efficacy, academic achievement and gender in analytical chemistry at DebreMarkos College of teacher education. African Journal of Chemical Education, 3(1), 328.

[17] Von Ah, D., Ebert, S., Ngamvitro, A., Park, N., \& Kang, D. (2004). Predictors of health behavior in College students. Journal of Advanced Nursing, 48(5), 125-134.

[18] Zajacova, A., Lynch, S. M., \&Espenshade, T. J. (2005). Self-efficacy, stress, and academic success in college. Research in higher education, 46(6), 677-706.

\section{APPENDIX}

Questionnaire

1, My lecturer help me when I get stuck on my academic tasks.

2, I can study and do other things that are not related to my study.

3 , I study every course thoroughly before any test given by the lecturer.

4, I finish up my tasks if I have any before I go to school every day.

5 , I pay attention and confidence during every lecture.

6, I can succeed and understand all my courses in the College.

7 , I help my parents with some work and do my study at the same time with confidence.

8 , I confidently feel that I can pass my test/exams with good grade. 